\title{
Os organismos comunitários em saúde mental no Quebec, Canadá
}

\section{| ${ }^{1}$ Carina Furlaneto Frazatto, ${ }^{2}$ Karen Roberta Steagall Bigatto |}

Resumo: Este estudo apresenta os organismos comunitários em saúde mental (OCSM) do Quebec, Canadá. Especificamente, traça reflexóes considerando sua origem, inserção no sistema público de saúde, princípios, características e formatos. Os OCSM são serviços autônomos, originados na comunidade, que oferecem atividades sem fins lucrativos no setor da saúde e assistência social. Realizou-se estudo descritivo, de abordagem qualitativa, com revisão não sistemática da literatura. Os resultados apontaram o surgimento dos OCSM no contexto de desospitalização de pacientes, mas com déficit de recursos substitutivos ao hospital psiquiátrico. Apontaram também sua consolidação como alternativa à psiquiatria tradicional, reconhecimento e financiamento parcial, pelo governo, como parte da assistência à saúde mental. Constatou-se que os OCSM compartilham certos princípios, mas concretizam-se em vários formatos, destacando-se por estimular a defesa dos direitos e a convivência em comunidade de pessoas em sofrimento psíquico. Contudo, observaram-se limitaçóes quanto ao alcance e à interação entre OCSM e estabelecimentos públicos, e questionase o papel do Estado frente a tais organismos. Conclui-se apontando aproximaçôes e distanciamentos entre características da assistência em saúde mental promovida pelos OCSM no Quebec e pelo Brasil; e indica-se a continuidade das discussóes, visando à sedimentação de políticas e práticas em saúde mental, que garantam o cuidado na comunidade.

> Palavras-chave: saúde mental; organismos comunitários em saúde mental; Quebec.
1 Universidade Estadual de Maringá (UEM). Maringá-PR, Brasil (caryfrazatto@hotmail.com). ORCID: 0000-0001-8533-8067

${ }^{2}$ Universidade Adventista de São Paulo. Juquitiba-SP, Brasil (karen. bigatto@gmail.com). ORCID: 0000-0002-2643-0848

Recebido em: 08/11/2018 Revisado em: 07/01/2019 Aprovado em: 15/01/2019 


\section{Introdução}

Este artigo visa apresentar os organismos comunitários em saúde mental (OCSM), serviços que atuam na assistência às pessoas em sofrimento psíquico ${ }^{2}$ na província de Quebec, (Leste do Canadá). Refletiremos sobre sua origem, inserção no sistema público de saúde, princípios compartilhados, características e formatos que assumem, bem como sobre possíveis contribuições e limites na assistência em saúde mental no Quebec.

De acordo com a Política de Saúde Mental do Quebec, para que um serviço seja caracterizado como um dos organismos comunitários, ele precisa atender a quatro condiçôes: ter origem na comunidade; oferecer atividades sem fins lucrativos no setor de saúde e serviço social; ser autônomo e compor seu conselho de administração majoritariamente por pessoas da comunidade; contar com suporte (por exemplo, financeiro) da comunidade que contribua, em parte, para seu funcionamento (QUÉBEC, 1989). Eles podem ser direcionados a diferentes públicos e causas, tais como aos imigrantes, jovens, mulheres, população vulnerável, entre outros. No caso dos que atuam no campo da saúde mental, são representados pelo Agrupamento de Recursos Alternativos em Saúde Mental do Quebec ${ }^{3}$ (RRASMQ), que os define como serviços que coadunam abordagens e práticas alternativas àquelas propostas pelo modelo biomédico, bem como possuem formas diferenciadas de acolher o sofrimento psíquico (REGROUPEMENT..., 2018).

No Quebec, assim como em muitos lugares do Mundo Ocidental, a atenção à saúde mental é historicamente marcada pela assistência realizada em instituições psiquiátricas. Embora sob alvo de críticas, tal modelo foi predominante até a década de 1960, período em que começaram a se desenvolver alternativas mais consistentes de cuidado na comunidade, com a emergência dos OCSM.

Considera-se que o questionamento às práticas derivadas do modelo clássico da psiquiatria — que resultaram no isolamento e na cronificação de milhares de pessoas por todo o mundo - é partilhado por profissionais, usuários e pesquisadores da saúde mental, brasileiros e quebequenses. No caso brasileiro, o movimento de Reforma Psiquiátrica, em curso no país desde a década de 1980, tem defendido de forma incessante o fim das internaçôes em hospitais psiquiátricos e a construção de um novo lugar social para a loucura, que possibilite a convivência com o diferente e o cuidado no território onde as pessoas vivem (AMARANTE, 2015). 
É importante lembrar que o processo de Reforma Psiquiátrica brasileira foi inspirado em outras tentativas de reformar a assistência neste campo ao redor do mundo. Inspirado em preceitos, acertos, e até mesmo levando em conta erros da reforma psiquiátrica italiana, da organização por setores do modelo francês ou mesmo da psiquiatria preventiva desenvolvida nos Estados Unidos, o modelo de atenção à saúde mental brasileiro é reconhecido internacionalmente, apesar das dificuldades e desafios enfrentados para sua consolidação (AMARANTE, 2015; DESVIAT, 2015; PITTA, 2011). Assim, o conhecimento acerca de realidades distintas da brasileira, sobre outros sistemas de saúde, modos de funcionamento e formas de pensar e prestar o cuidado à saúde mental pode se constituir em ferramenta para a reflexão e construção de saberes e práticas neste campo de atuação.

O interesse em desenvolver este estudo surgiu durante a realização de estágio de doutorado sanduíche no exterior pelas autoras junto à Escola de Serviço Social da Universidade de Montreal e à Equipe de Pesquisa e Ação em Saúde Mental e Cultura $^{4}$ (ÉRASME). A partir de visitas a pontos da rede de atenção, de conversas com funcionários, gestores e usuários, da participação em discussões e eventos, bem como de estudos acerca da história e da política de saúde, especialmente da saúde mental no Quebec, notou-se o papel estratégico dos organismos comunitários na assistência em saúde mental na província. Essa observaçáo instigou o aprofundamento dos conhecimentos acerca dos OCSM e, posteriormente, a construção de reflexôes sobre esta modalidade de assistência no campo da saúde mental.

\section{Procedimentos metodológicos}

Trata-se de um estudo descritivo de abordagem qualitativa, baseado em revisão não sistemática da literatura que aborda a rede de atenção à saúde mental do Quebec, em particular os organismos comunitários em saúde mental. A revisão da literatura foi realizada por meio de pesquisas no Erudit — site canadense que agrega publicaçóes do campo das ciências humanas e sociais; na Biblioteca da Universidade de Montreal; e no acervo físico e digital da ÉRASME e da Aliança Internacional de Pesquisa Universidades-Comunidades Saúde Mental e Cidadania (ARUCI-SMC). Também foram feitas buscas a partir das referências dos artigos encontrados. Ainda foram consultados documentos oficiais do governo do Canadá e do Quebec, tais como a Lei Canadense de Saúde (QUÉBEC, 2018), o Plano de Ação em Saúde 
Mental mais recente (QUÉBEC, 2015) e outros documentos que dispõem sobre os estabelecimentos de saúde do Quebec e a Rede de Atenção à Saúde. Os resultados foram organizados e são apresentados em três temas: a atenção à saúde mental no Quebec e a emergência dos OCSM; classificaçôes; contribuiçôes e limites.

\section{A atenção à saúde mental no Quebec e a emergência dos OCSM}

No Quebec, como em grande parte dos países ocidentais, durante o século XIX, aqueles que sofriam psiquicamente e outros públicos marginalizados eram, em geral, isolados da sociedade e, muitas vezes, institucionalizados. As instituiçóes voltadas para as pessoas em sofrimento psíquico começaram a funcionar em 1838, com a inauguração do primeiro asilo, que foi seguida da construção de outros similares. Desde o início, tais instituiçóes foram criticadas devido às suas péssimas condições. Ao longo dos anos, ocorreram algumas tentativas de desospitalização, bem como foram abertos ambulatórios e clínicas psiquiátricas que, contudo, não chegaram a se propagar, ou mesmo se consolidar como uma alternativa de grande alcance à assistência oferecida pelos hospitais psiquiátricos. Mesmo após a Segunda Guerra Mundial, quando em todo o mundo as consequências das internaçóes psiquiátricas passaram a ser profundamente questionadas, no Quebec, os asilos se mantiveram ocupando um lugar central na assistência à saúde mental, a despeito do direcionamento de subsídios para esta área, que visava a favorecer práticas mais modernas (FLEURY; GRENIER, 2004).

Em meados da década de 1960, o processo de desinstitucionalização de pacientes psiquiátricos no Quebec se fortaleceu, por meio de denúncias da situação dos internos, que apontavam para a necessidade de humanizar as instituiçóes e práticas psiquiátricas. Esse movimento tinha como objetivo o acompanhamento e a assistência aos usuários fora do hospital psiquiátrico, privilegiando, portanto, os serviços de base comunitária. A publicação do livro Os loucos gritam por socorro 5 , de Pagé (1961), contribuiu para este processo na medida em que o autor, um expaciente, expôs a situação caótica do cuidado oferecido nos hospitais psiquiátricos (DESVIAT, 2015; RODRIGUEZ; CYR, 2018).

Segundo Fleury e Grenier (2004), esse movimento aconteceu no contexto da chamada Revoluçáo Tranquila ${ }^{6}$ e da chegada do Partido Liberal ao governo da província, o qual trazia propostas que visavam a modernizar a economia e a sociedade quebequense. $\mathrm{O}$ momento histórico favoreceu a resistência ao predomínio 
da assistência asilar à pessoa em sofrimento psíquico, o surgimento dos organismos comunitários e a mobilizaçáo em favor de modificaçóes no campo do Direito que permitissem avanços na assistência em saúde mental.

Entre os anos de 1965 e 1975 se deu a primeira grande onda de desospitalização, período em que foram fechados 5.789 leitos em hospitais psiquiátricos, número que correspondia a $28 \%$ do total existente. Essa diminuição no número de leitos foi acompanhada da transformação dos grandes asilos em hospitais menores; da busca por reduzir o tempo de internação; da implantação de serviços de moradia na comunidade; da implantação de alas psiquiátricas em hospitais gerais; e do aumento do número e diversidade dos profissionais no cuidado em saúde mental. Entretanto, a rapidez desse processo sem a mesma agilidade na implantação de outros dispositivos de atenção fez com que muitas pessoas ficassem sem abrigo ou assistência, e gerou um aumento da judicialização dos comportamentos associados à loucura, além de provocar o aumento do fardo familiar e a "síndrome da porta giratória", ou seja, altas seguidas de reinternaçóes (FLEURY; GRENIER, 2004; GAGNON, 2007; RODRIGUEZ et al., 2006).

Além disso, os militantes do campo da saúde mental consideravam que as mudanças na organização dos serviços, por si só, além de insuficientes, não tinham resolvido os problemas até então identificados, tendo em vista que não era possível verificar diferenças entre a assistência oferecida pelos hospitais gerais e pelos hospitais psiquiátricos. A título de exemplo, apontavam que o público atendido na saúde mental ainda permanecia medicalizado de forma exacerbada e não tinha uma participação efetiva na comunidade. Ou seja, indicavam que, embora a instituição psiquiátrica tivesse passado por mudanças, as formas de assistência permaneciam as mesmas (RODRIGUEZ; CYR, 2018).

O incômodo causado pela hospitalização prolongada, pela desospitalização irresponsável dos casos e pela desassistência aos problemas de saúde mental atingiu a sociedade civil, favorecendo o surgimento dos OCSM, encabeçados, em sua maioria, por profissionais que tinham experiência na rede de saúde e serviços sociais ou mesmo em organismos comunitários direcionados a outros públicos que não do campo da saúde mental (RODRIGUEZ; CYR, 2018).

Importante mencionar que o processo de emergência dos OCSM se deu paralelamente à implantaçáo do sistema de saúde pública do Quebec, iniciada em meados da década de 1970. A originalidade desse sistema de saúde foi a inclusão 
dos serviços sociais, o que levaria os problemas de saúde e as questóes psicossociais a não serem tratadas separadamente, mas a partir de uma visão global e complexa (GRENIER; BOURQUE, 2016).

O sistema de saúde e serviços sociais quebequense, embora de caráter provincial, esteve, desde o princípio, submetido à Lei Canadense de Saúde, que prevê repasse financeiro às províncias, contanto que estas efetivem seus sistemas de saúde a partir de cinco princípios: gestão pública, integralidade, universalidade, acessibilidade e transferabilidade (garantia de ressarcimento se o usuário necessitar de atendimento em saúde em outras províncias ou outros países). A mencionada lei também orienta a organização dos serviços de saúde em níveis de atenção:

1) serviços de primeira linha (première ligne), que são de base territorial e possuem dupla função: ofertar diretamente os cuidados em termos de atenção primária e coordenar a atenção recebida pelo usuário em outros serviços, para garantir a continuidade do cuidado e o acesso a outros equipamentos de saúde;

2) serviços de segunda linha (deuxième ligne), que se referem aos serviços hospitalares e aos estabelecimentos que prestam cuidados de longa duração, como os centros de alojamento e de cuidados paliativos;

3) serviços de terceira linha (troisième ligne), que correspondem à atenção especializada e suplementar, como a fisioterapia, a odontologia, ou ainda a oftalmologia, e o setor de materiais, equipamentos e aparelhos médicos (CANADA, 2017).

Esse sistema público e universal, segundo Grenier e Bourque (2016), necessita estar em consonância com as necessidades da população, proporcionar facilidade de acesso e não dar lugar para o privado. É interessante ressaltar que o início do processo de reconhecimento dos OCSM pelo Ministério de Saúde e de Serviços Sociais $^{7}$ (MSSS) se deu no começo dos anos 80, justamente em um período de crise econômica e de questionamentos ao redor do Estado de Bem-Estar Social (GRENIER; FLEURY, 2014), favorecendo com que eles se concretizassem como uma alternativa ao público, sem se caracterizar como serviço privado.

Mercier e White (1995) consideram que o surgimento dos Organismos Comunitários se deu com a intenção de melhorar o acesso da população aos serviços de suporte na comunidade. Para as autoras, o desenvolvimento de recursos comunitários foi um processo informal, que partiu de pessoas da comunidade, e se 
desenvolveu de diferentes formas de uma localidade a outra. Eles se caracterizam como um conjunto vasto de organizaçóes que repousam sobre a ação voluntária e autônoma de grupos sociais situados fora do Estado e da organização privada, com o objetivo comum de fazer com que os fundos públicos fossem utilizados para o financiamento de serviços alternativos e complementares ao hospital psiquiátrico.

Nesta mesma direção, Rodriguez et al. (2006) compreendem que a emergência desse recurso no campo da saúde mental foi propiciada quando cidadãos, pessoas tocadas diretamente pelos problemas de saúde mental, criaram serviços e uma rede de organismos de defesa de direitos que até hoje contribuem para enriquecer a concepçáo acerca dos transtornos mentais e para a experimentaçáo de práticas diferentes daquelas do modelo clássico da psiquiatria. Por meio de suas açôes, foi aberta a possibilidade para que pessoas — até então consideradas absolutamente passivas - tivessem condições de se expressar, propiciando um aumento de políticas e programas direcionados a esse público. Uma parcela desses serviços, emergidos da comunidade, veiculava uma crítica radical às práticas asilares e biomédicas, enquanto outros se colocavam como complementares ao sistema público de assistência à saúde mental e ao modelo de atenção tradicional.

Conforme demonstram Grenier e Fleury (2009, 2014), até o ano de 1981, 49 OCSM haviam sido fundados, principalmente voltados para a promoção em saúde mental. Entre 1982 e 1988, a maioria dos serviços criados era centros de crise e de escuta, recursos de moradia e aqueles voltados para o acompanhamento dos usuários. Entretanto, segundo Rodriguez e Cyr (2018), até 1989 ainda faltavam recursos comunitários e, diante do transtorno mental, os familiares se viam apenas com a opção da internação psiquiátrica; se o usuário recusava a internação, não havia recursos suficientes na comunidade que pudessem assisti-lo.

Em 1989, a província de Quebec instituiu sua Política de Saúde Mental. Constituída como uma das primeiras políticas implantadas nesta área mundialmente, seus objetivos e orientaçóes visam a assegurar que o cuidado seja centrado na pessoa, melhorar a qualidade da assistência e dos serviços, favorecer a equidade, buscar soluçôes no meio de vida das pessoas e consolidar parcerias (QUÉBEC, 2015). Ao promulgar os termos da Política de Saúde Mental, reconheceu-se que, já naquela época, a abordagem comunitária teria proporcionado avanços que contribuíram para a passagem de um sistema asilar para um sistema pautado na integração social. Considerou-se, também, que a adoção de novas abordagens possibilitou a promoção 
de novas práticas e a diversificação de serviços. Assim, o MSSS reconhece o potencial dos organismos comunitários na área de saúde mental, propondo-se a apoiá-los para que desenvolvam o seu papel na comunidade e tenham uma participação efetiva na organização dos serviços de saúde mental em cada região do Quebec. O MSSS declara ainda privilegiar as soluçóes que emergem do meio onde as pessoas vivem e subvencioná-las, favorecendo a manutenção e a integração desses serviços (QUÉBEC, 1989). O reconhecimento oficial dos OCSM pelo governo se deu em 1991, a partir da aprovação de um projeto de lei que favorecia sua implantação (GRENIER; FLEURY, 2014).

O apogeu da fundação de organismos comunitários dedicados às questóes de saúde mental se deu entre 1989 e 1998. Nessa época, prosperaram os grupos de defesa dos direitos, de ajuda aos familiares e pessoas próximas, de ajuda mútua, de meio de vida e de integração ao trabalho. Foi também nesse período que tais organizaçóes deixaram de ser apenas responsabilidade da sociedade civil e começaram a receber subvenção do Estado, conforme proposto pela Política de Saúde Mental então apresentada. Assim, novos Organismos foram criados de modo que dados do MSSS apontam para 412 OCSM cadastrados em 2012-2013 (GRENIER; FLEURY, 2009, 2014).

O Plano de Ação em Saúde Mental (PASM) do Quebec — documento que compóe a política oficial de saúde mental, periodicamente reformulado e publicado, que orienta e direciona diretrizes para o cuidado em saúde mental - em sua edição mais recente, ou seja, o PASM 2015-2020, assegura que a melhora das práticas em saúde mental não pode se realizar sem a mobilização, colaboração e implicação de diferentes parceiros, incluindo os OCSM. Considera que estes são significativamente responsáveis pela melhora da qualidade de vida e da participação social das pessoas usuárias dos serviços, e que contribuem para uma assistência diversificada e adaptada às necessidades dos usuários e das pessoas próximas a eles. O Plano de Ação em questão defende que haja suporte financeiro adequado aos OCSM, que permita a oferta de serviços de qualidade, determinando que, do total de gastos em saúde mental, no mínimo, 10\% sejam direcionados aos OCSM (QUÉBEC, 2015). O MSSS, através do Programa de Apoio aos Organismos Comunitários, é o principal financiador dos OCSM. Em 2003, 64\% do orçamento deles provinham deste programa, enquanto a segunda maior fonte provinha de autofinanciamento, e outras fontes de verba vinham de programas ou projetos pontuais (GRENIER; FLEURY, 2009). 
Desde sua emergência até o momento, diferentes experiências de OCSM foram alavancadas no Quebec, assumindo variados formatos, porém se coadunando com uma filosofia de trabalho que orienta suas práticas, conforme veremos nos próximos itens.

\section{Classificaçóes}

Os organismos comunitários, incluindo os que atuam no campo da saúde mental, são regulamentados pela "Lei sobre os Serviços de Saúde e Serviços Sociais", 8 publicada pela primeira vez em 1991, e atualizada em 2018. Esta lei concebe que eles sejam instituídos como pessoa jurídica, por meio de lei ou resolução do Quebec. Eles não devem ter finalidade lucrativa e precisam ser geridos por um conselho de administração composto, em sua maioria, por usuários dos serviços ou membros da comunidade. Recebem subvenção pública e definem livremente suas orientações, políticas internas e abordagens. Ao fim de cada período de subvenção, cada um deles tem até três meses para transmitir um relatório financeiro (QUÉBEC, 2017).

Os OCSM têm em comum uma abordagem psicossocial, considerando a pessoa em sua integralidade, de forma horizontal, com açóes ancoradas na comunidade (GRENIER; FLEURY, 2014). Eles oferecem serviços, tais como apoio aos usuários e seus próximos, acompanhamento na comunidade, atividades de adaptação, moradia, integração ao trabalho e estudos, defesa dos direitos, informação, escuta qualificada por telefone, intervenção na crise e prevenção do suicídio. Eles procuram ainda atuar na direção de oferecer propostas e soluções a diversos pontos priorizados pelos Planos de Ação em Saúde Mental do Quebec, tais como a participação dos usuários e de pessoas próximas a ele no planejamento e organização dos serviços, a luta contra o estigma, a promoção e a prevenção dos transtornos mentais. Para tanto, assumem diferentes formatos que resultam em várias formas de classificação, de acordo com diferentes estudiosos.

Mercier e White (1995), considerando o local de sua emergência e atuação, somando essas características aos seus modos de intervenção, propóem a seguinte classificação:

a. centrados no estabelecimento: são completos do ponto de vista da diversidade dos serviços, oferecendo condiçôes favoráveis ao acompanhamento e continuidade; porém, em geral, estão sujeitos a uma abordagem psiquiátrica altamente especializada, que tende a ser controladora e romper com o meio de vida dos usuários; 
b. alternativos: opostos ao anteriores, evitam o controle profissional e buscam engajar os antigos usuários como membros, permanecendo em estreito contato com o ambiente onde vivem os usuários; por outro lado, não oferecem um suporte completo de cuidado comunitário, podendo haver carências no que se refere a algumas necessidades do tratamento;

c. orientados no planejamento da comunidade: repousam sobre os recursos locais, visando a reestruturá-los e profissionalizá-los assim como adotar novos programas; surgem do meio natural, contudo, são mais controladores que os anteriores;

d. grupos comunitários: permitem maior acesso dos usuários aos lugares de administração e poder dentro dos serviços, porém, não garantem acesso aos lugares políticos, nos quais poder-se-ia debater sobre suas finalidades, mais do que seus meios de atuação.

Outra forma de classificação é proposta por Gagné (1996), levando-se em conta o objetivo de ação dos OCSM:

a. recursos de autoajuda: grupo de pessoas que querem dividir suas experiências, o que também se constitui em possibilidade de romper com o isolamento social;

b. recursos de integração social: promovem atividades mais estruturadas do que os grupos de ajuda mútua, incluindo, por exemplo, atividades de reinserçáo ao trabalho, cursos e estágios supervisionados;

c. recursos terapêuticos: não são muito numerosos, abrangem os chamados centros de crise e alguns recursos de terapias de grupos.

Por fim, Grenier e Fleury (2014) propóem a seguinte forma de classificar os OCSM, de acordo com seus objetivos e a população-alvo:
a. organismos de promoção à saúde mental para população em geral;
b. centros de crise, de escuta e prevenção do suicídio direcionados à população em geral e à população com transtornos mentais;
c. grupos de ajuda aos familiares e próximos;
d. grupos de convivência, incluindo os centros de dia ou de noite;
e. grupos de autoajuda;
f. recursos habitacionais; 
g. organismos de seguimento na comunidade, que propóe o acompanhamento de pessoas em sofrimento psíquico por profissionais em seu cotidiano;

h. organismos de integração ao trabalho;

i. grupos de defesa dos direitos.

Os cinco últimos servem, principalmente, à população com transtornos mentais graves.

A Política de Saúde Mental do Quebec reconhece a variedade e a diversidade dos OCSM, e a consequente dificuldade em classificá-los. Dessa forma, é proposta a classificação em apenas dois tipos: grupos que oferecem serviços diretamente às pessoas que vivem com transtornos mentais; grupos de ajuda mútua, que se referem a grupos de pessoas que se unem na busca por encontrar respostas às situaçóes que lhes causam sofrimento (QUÉBEC, 1989).

As diferentes formas de classificação dão sinais da amplitude e variedade que os OCSM assumem no cotidiano e de como concretizam suas práticas. Entretanto, para além dos formatos que se apresentam, Mercier e White (1995) asseguram que é a abordagem utilizada por eles que deve ser ressaltada. Segundo as autoras, há um discurso consensual e certo número de objetivos que deve ser aplicado a todos os níveis de ação dos OCSM, perpassando o planejamento, a prestação de serviços e as práticas de intervenção. Descreveremos a seguir os aspectos que compóem tal discurso consensual e, a partir deles, refletiremos sobre possíveis contribuições e limites dos OCSM.

\section{Contribuiçóes e limites}

Para o MSSS, os objetivos comuns aos Organismos Comunitários voltados ao público da saúde mental são: oferecer serviços de prevenção, ajuda e suporte, incluindo os serviços de alojamento temporário; realizar atividades que visem à promoçáo e à defesa dos direitos e dos interesses das pessoas que utilizam os serviços de saúde e serviços sociais; promover o desenvolvimento social, a melhora de condiçôes de vida e saúde; responder a novas necessidades, utilizando novas abordagens ou visar a grupos específicos de pessoas (QUÉBEC, 2017).

Alguns desses aspectos são reforçados no PASM 2015-2020, no qual os Organismos Comunitários são vistos como capazes de possibilitar a formação de grupos fundamentais para garantir a participação dos usuários (QUÉBEC, 2015). 
Esse é um dos objetivos centrais de grande parte dos OCSM, que procuram pelos usuários e os convidam a ocuparem lugares centrais, garantem-lhes o direito à fala $\mathrm{e}$ facilitam com que façam parte da elaboração das políticas públicas que lhes dizem respeito (RODRIGUEZ; CYR, 2018).

O PASM 2015-2020 também considera que os OCSM são essenciais na defesa de direitos das pessoas em sofrimento psíquico e no reconhecimento das necessidades das pessoas ao seu redor, e na luta contra a estigmatização e discriminação dos sujeitos (QUÉBEC, 2015). Os Organismos Comunitários que atuam sob a orientação da defesa de direitos, em muitos casos, também se responsabilizam pela assistência, mas priorizam a orientação às pessoas sobre como ter acesso às informações e garantir sua cidadania. Um exemplo é deixar claro para o usuário quanto ao consentimento livre e esclarecido em situaçóes mais invasivas, tais como a aplicação de eletrochoques (RODRIGUEZ; CYR, 2018).

De modo geral, o MSSS reconhece os OCSM como parceiros fundamentais para melhorar a saúde mental da populaçáo, as práticas organizacionais e clínicas, a qualidade de vida e a participação social das pessoas usuárias (QUÉBEC, 2017). Nesta mesma direção, Grenier e Fleury (2014) apresentam estudos internacionais cujos resultados têm apontado os efeitos positivos dos OCSM sobre os usuários, mostrando que eles favorecem a melhora dos usuários, a confiança em si, a construção de uma rede social, a aquisição de novas atitudes, a melhor defesa dos direitos dos usuários, a redução do estigma, o acesso fácil a algum tipo de assistência, a diminuição de internações psiquiátricas e a redução de sintomas psíquicos. $\mathrm{Na}$ concepção de Rodriguez e Poirel (2011), todos esses aspectos demonstram que a assistência proporcionada pelos OCSM contribui para humanizar o cuidado e racionalizar as despesas na área da saúde mental.

Tais benefícios, de acordo com o RRASMQ, estão associados à maneira com que muitos dos OCSM intervêm, especialmente os mais de cem filiados a esta entidade, que compartilham uma filosofia alternativa no que se refere à interpretação, concepção e formas de assistência ao sofrimento psíquico. Isso significa que esses serviços atuam não mais sob a ótica biomédica, com práticas centradas no hospital ou na instituição, mas com intervençôes de base comunitária que visam a permitir que a pessoa permaneça onde ela vive (RODRIGUEZ et al., 2006). Ou seja, o modelo biomédico é visto de forma crítica, ainda que haja diferenças na forma como cada OCSM coloca essa crítica em prática. Por exemplo, em alguns casos, 
as discussôes sobre o diagnóstico e a medicação não são levadas em conta; já em outros, tais recursos terapêuticos são analisados criticamente e há casos em que o diagnóstico médico é absolutamente recusado (RODRIGUEZ, 2011).

De modo geral, os OCSM no Quebec têm proporcionado novas maneiras de pensar, agir e intervir frente ao transtorno mental, diferentes dos modelos tradicionais de atenção. Com isso, eles têm facilitado o acesso da população à assistência em saúde mental, inclusive para pessoas que não chegavam a ser contempladas pela assistência ofertada nos serviços ligados diretamente ao MSSS.

Apesar dos aspectos positivos já mencionados, há algumas limitações relacionadas à efetividade dos OCSM. Para Rodriguez e Poirel (2011), embora exista consenso quanto às orientaçóes e implicaçóes de sua organização, as consequências quanto à mudança da assistência da instituição psiquiátrica para a comunidade, bem como a transformação das práticas e da concepção do tratamento, ainda não estão totalmente demonstradas, carecendo ampliar os estudos neste sentido.

Rodriguez e Cyr (2018) mencionam que alguns militantes dos OCSM consideram necessária maior aproximação entre esses serviços e aqueles do sistema público de saúde e serviços sociais. Essa aproximação poderia favorecer a participação dos usuários na elaboração dos planos regionais direcionados à organização dos serviços. Segundo Grenier e Fleury (2014; 2009), apesar de existir certa colaboração entre a rede de serviços vinculada diretamente ao MSSS e os OCSM, tal parceria acontece, em sua maioria, por parte daqueles Organismos classificados como conservadores ou moderados e, raramente, é formalizada. Essas parcerias estão mais presentes entre os Organismos Comunitários que trabalham com a promoção da saúde mental, seguidos daqueles que promovem a integração ao trabalho e, em menor medida, pelos grupos de ajuda mútua e defesa de direitos.

Em publicação posterior, Grenier e Fleury (2014) reconhecem que as açóes dos OCSM ainda são pouco conhecidas, ou reconhecidas como importantes, e consequentemente pouco aproveitadas pelos profissionais de saúde da rede pública. Estudos apontam que muitos profissionais que trabalham nestes serviços não têm contato com os OCSM. Entre os médicos, a proporção de profissionais que não trabalha em conjunto com os Organismos Comunitários chega a 94\%.

Se, por um lado, autores apontam para a necessidade de cautela na parceria entre os OCSM e os serviços ligados diretamente à rede pública, para que aqueles não percam sua autonomia (RODRIGUEZ; CYR, 2018), por outro lado, Gagné (1996) 
já alertava que as atividades realizadas pelos OCSM não devem ser confundidas com aquelas promovidas pelos serviços vinculados diretamente ao MSSS. Para a autora, não se deve aceitar que as açôes de atribuição dos serviços públicos sejam substituídas pelas dos Organismos Comunitários, a preços mais baixos e menos recursos.

\section{Considerações finais}

Vimos que os OCSM têm se destacado como importantes dispositivos de base comunitária na atenção à saúde mental no Quebec. Tais dispositivos atuam na defesa de direitos, buscam fortalecer a participação dos usuários e propor recursos terapêuticos na comunidade, contrapondo-se, dessa forma, aos modelos tradicionais de atenção, que centram sua ação nos sintomas apresentados pelos usuários e, muitas vezes, consideram a possibilidade do isolamento como proposta com finalidade terapêutica, assim como privilegiam o uso de medicamentos. Este estudo mostrou que o Estado reconhece o potencial dos OCSM, como recursos alternativos na assistência à saúde mental, incluindo estes dispositivos como parte da rede de atenção. No entanto, oferece pouco apoio a estes recursos comunitários (GAGNON, 2007). O governo do Quebec assume, apenas, o compromisso de financiá-los parcialmente. Não toma para si, porém, outras responsabilidades, mesmo que compartilhadas, como com relação à gestão, à definição de diretrizes gerais e à operacionalização dos serviços, funçôes que recaem sobre a sociedade civil.

As reflexôes empreendidas neste texto indicaram que a discussão sobre o lugar ocupado pelo Estado e pelos Organismos Comunitários na assistência à pessoa em sofrimento psíquico deve ser feita com cautela. A origem e base de atuação dos OCSM na comunidade, bem como sua autonomia de ação - característica valorizada pelos estudiosos sobre o tema —, podem favorecer o surgimento de serviços sustentados na demanda real do território; o aproveitamento dos recursos da comunidade; a proximidade com o usuário; e a promoçáo de seu protagonismo. Por outro lado, podem indicar a transferência da responsabilidade pelo cuidado ampliado em saúde mental do Estado para a sociedade civil. Neste sentido, podemos sugerir, considerando a história da emergência dos OCSM, que eles surgiram para preencher uma lacuna, entre a desospitalização dos pacientes de instituiçôes psiquiátricas e a garantia de assistência integral a esses usuários. Além disso, é necessário considerar que a ausência de diretrizes governamentais pode dificultar 
a fiscalização de serviços e práticas, comprometendo, até mesmo, o acesso, o acolhimento e o acompanhamento do usuário no serviço mais adequado para suas necessidades, bem como sua segurança e a garantia de seus direitos.

Embora este estudo não tenha objetivado traçar um paralelo entre características da assistência em saúde mental no Quebec, protagonizada pelos OCSM, e no Brasil, foi possível observar aproximaçôes e distanciamentos entre propostas e práticas destes dois lugares. Ambos privilegiam a realização do cuidado no território onde as pessoas vivem; nascem da crítica às formas de assistência desenvolvidas nos hospitais psiquiátricos, estendendo-a ao modelo biomédico; partem da mobilização de trabalhadores, usuários e familiares; buscam uma transformação na lógica da atenção à saúde mental, visando a humanizar o cuidado, e também racionalizar as despesas nesta área. Há um histórico de redução de leitos em hospitais psiquiátricos tanto no Brasil quanto no Quebec, e a criaçáo de redes alternativas de cuidados, incluindo implantação de serviços na comunidade e leitos em hospitais gerais. Também podemos dizer que ambos anseiam pela participação social, seja pela chamada Participação Cidadāa no Quebec ou pelo "controle social" no Brasil. Ainda, ambos enfrentam dificuldades de financiamento para efetivação de seus princípios.

Apesar de todas essas semelhanças, a forma como se concretiza o cuidado em saúde mental no Brasil e pelos OCSM no Quebec apresenta diferenças significativas. No caso brasileiro, a concretização de uma nova forma de assistência nesta área se deu pela via da política pública de saúde, com a promulgação de leis e normas e a implantação de uma rede de serviços que visavam a substituir os manicômios, de acordo com o movimento social de Reforma Psiquiátrica brasileira, iniciado na década de 1980. Os serviços de saúde mental brasileiros seguem diretrizes federais, bem como diversas recomendações que favorecem a integração entre eles e também com outros setores. No Quebec, os OCSM se constituem como serviços alternativos, não propriamente substitutivos, aos serviços tradicionais de assistência em saúde mental, que incluem os hospitais psiquiátricos, e outros serviços da rede pública de saúde, os quais orientam suas práticas em acordo ao modelo biomédico. $\mathrm{Na}$ figura dos OCSM, a concretização de outras formas de atenção em saúde mental se dá pela via da sociedade civil organizada e não segue uma padronização; pelo contrário, apresenta grande variedade de formatos e estratégias, e não existe uma política que direcione seu funcionamento e vise à integração entre os OCSM, ou mesmo entre 
estes e os serviços da rede pública de saúde. Ainda, observamos que no Brasil há movimentos sociais em prol da Luta Antimanicomial, que recusam os hospitais psiquiátricos e todas as formas de assistência derivadas deste modelo. Já no Quebec, a forma alternativa de assistência protagonizada pelos OCSM, embora organizada em agrupamento, mantém um discurso de resistência pela via do indivíduo, com a ideia de potencializá-lo para a garantia de seus direitos.

Continuar os diálogos sobre os OCSM no Quebec pode ser uma forma de sedimentar políticas e práticas em saúde mental mais abrangentes, humanizadas, sob o paradigma psicossocial, baseadas na comunidade e no meio de vida das pessoas. É necessário avançar com relação ao alcance, à efetividade das açôes e à integração entre os serviços. Refletir sobre diferentes experiências, práticas, políticas e sistemas de saúde pode proporcionar ferramentas para novos arranjos, para responder aos desafios no campo da saúde mental, sempre guiados pelo entendimento de que $a$ liberdade é terapêutica. ${ }^{10}$

\section{Referências}

AMARANTE, P. Teoria e critica em Saúde Mental. Rio de Janeiro: Fiocruz, 2015.

CANADA. Loi Canadienne sur la santé: Loi concernant les contributions pécuniaires du Canada ainsi que les principes et conditions applicables aux services de santé assurés et aux services complémentaires de santé. Loi Revisée du Canada, 1985. ch. C-6. Disponível em: <http://lawslois.justice.gc.ca/fra/lois/c-6/TexteComplet.html>. Acesso em: 15 ago. 2017.

CONILL, E. M. A recente reforma dos serviços de saúde na província do Québec, Canadá: as fronteiras da preservação de um sistema público. Cadernos de Saúde Pública, v. 16, n. 4, p. 963-971, 2000.

DESVIAT, M. A Reforma Psiquiátrica. 2. ed. Rio de Janeiro: Fiocruz, 2015.

FLEURY, M. J.; GRENIER, G. Historique et enjeux du système de santé mentale québécois. Ruptures, revue transdisciplinaire en santé, v. 10, n. 1, p. 21-38, 2004.

GAGNÉ, J. L'approche alternative en santé mentale. Nouvelles pratiques sociales, v. 9, n. 2, p. 137-146, 1996.

GAGNON, S. La violence dans le traitemente de la folie au Québec. Aspects sociologiques, v. 14, n. 1, p. 89-112, 2007.

GRENIER, G.; FLEURY, M. J. Les organismes communautaires en santé mentale au Québec: rôle et dynamique partenariale. Santé mentale au Québec, v. 34, n. 1, p. 101-126, 2009. 
GRENIER, J.; BOURQUE, M. Les politiques publiques et les pratiques managériales: impacts sur les pratiques du travail social, une profession á pratique prudentielle. Forum, v. 1, n. 147, p. 8-17, 2016.

GRENIER, G.; FLEURY, M. J. Rôle du communautaire en santé mentale dans un système en evolution: état des connaissances et recommandations. Santé mentale au Québec, v. 39, n. 1, p. 119-136, 2014.

MERCIER, C.; WHITE, D. La politique de santé mentale et la communautarisation des services. Santé Mentale au Québec, v. 20, n. 1, p. 17-30, 1995.

PAGÉ, J. Les fous crient au secours. Montréal: Éditions du Jour, 1961.

PITTA, A. M. F. Um balanço da Reforma Psiquiátrica brasileira: instituições, atores e políticas. Ciência e Saúde Coletiva, v. 16, n. 12, p. 4579-4589, 2011.

QUÉBEC. Ministère de la Santé et des Services Sociaux. Politique de Santé Mentale. Québec, 1989. Disponível em: <http://publications.msss.gouv.qc.ca/msss/fichiers/2008/89-santementale.pdf>. Acesso em: 11 jun., 2018.

. Ministère de la Santé et des Services Sociaux. Plan d'action en santé mentale 20152020: Faire ensemble et autrement. Québec, 2015. Disponível em: < http://publications.msss. gouv.qc.ca/msss/fichiers/2015/15-914-04W.pdf>. Acesso em: 16 jul., 2017.

. Ministère de la Santé et des Services Sociaux. Établissements de santé et de services sociaux. Québec, 2017. Disponível em: <http://www.msss.gouv.qc.ca/reseau/etablissements. php>. Acesso em: 16 ago. 2018.

. Ministère de la Santé et des Services Sociaux. Loi sur les services de santé et les services sociaux. Québec, 2018. Disponível em: <http://legisquebec.gouv.qc.ca/fr/pdf/cs/S-4.2.pdf>. Acesso em: 13 mar., 2018.

REGROUPEMENT DE RESSOURCES ALTERNATIVES EM SANTE MENTALE DU QUEBEC. La santé mentale et l'Alternative. Disponível em: <http://www.rrasmq.com/>. Acesso em: 16 jun., 2016.

RODRIGUEZ, L.; CYR, C. "Un pouvoir fou”. La contribuition coomunutaire à l'avancemente des droits en santé mentale. In: SAILLANT, F.; LAMOUREUX, E. (Orgs.). InterReconnaissance: La mémoire des dorits dans le milieu communautaire au Québec. Québec: Les Presses de l’Université Laval, 2018.

RODRIGUEZ, L. Nouveaux paramètres pour l'élaboration des pratiques de soutien communautaire: contribuition des organismes communautaires et alternatifs au Québec. Santé Mentale au Québec, v. 36, n. 1, p. 35-56, 2011.

RODRIGUEZ, L.; POIREL, M. L. Le traitement dans la communauté. Enjeux et défis de bonnes pratiques en santé mentale et en psychiatrie. Santé Mentale au Québec, v. 36, n. 1, p. 7-12, 2011. 
RODRIGUEZ, L. et al. Repenser la qualité des services en santé mentale dans la communauté: changer de perspective. Québec: Presses de L’Université du Québec, 2006.

YASUI, S. Rupturas e encontros: Desafios da Reforma Psiquiátrica brasileira. Rio de Janeiro, Fiocruz, 2010.

\section{Notas}

${ }^{1}$ Esta pesquisa contou com financiamento da Coordenação de Aperfeiçoamento de Pessoal de Nível Superior (Capes) por meio de bolsa de doutorado sanduíche no exterior destinada às autoras no ano de 2017, por período de quatro e oito meses. Esteve em consonância ao Edital no19 da Capes, disponível em http://www.capes.gov.br/images/stories/download/editais/12072016-edital-n-19-PDSE.pdf.

${ }^{2}$ Pessoas em sofrimento psíquico, ou simplesmente pessoas em sofrimento, é a expressão utilizada nas publicações brasileiras, no âmbito da saúde mental e atenção psicossocial, que pretende designar a pessoa como um todo, e não apenas seus sintomas, valorizando seus desejos, potencialidades, autonomia e independência, em consonância com os princípios da Reforma Psiquiátrica (PITTA, 2011; YASUI, 2010). Nas publicações quebequenses, predomina a expressão personnes qui ont des problèmes de santé mentale, traduzida como "pessoas que têm problemas de saúde mental", cuja noção se aproxima daquela que descrevemos nas publicaçóes brasileiras, na medida em que não reduz a pessoa à patologia, mas a concebe como capaz de controlar sua vida, participar ativamente do cuidado que lhe é oferecido e ter seus direitos garantidos (QUÉBEC, 2017).

${ }^{3}$ Regroupement des Ressources Alternatives en Santé Mentale du Québec. Tradução nossa.

${ }^{4}$ Équipe de Recherche et D'Action en Santé Mentale et Culture. Tradução nossa.

${ }^{5}$ Le Fous Crient au Secours. Tradução nossa.

${ }^{6}$ Revolução Tranquila: caracteriza importantes transformaçóes econômicas e sociais que ocorreram no Quebec em meados de 1950. Passou de uma província rural, católica, dominada por elites tradicionais para uma sociedade capitalista, moderna e avançada (CONILL, 2000).

${ }^{7}$ Ministère de la Santé et des Services Sociaux. Tradução nossa.

${ }^{8}$ Loi sur la Santé et les Services Sociaux. Tradução nossa.

${ }^{9}$ Participation Citoyenne. Tradução nossa.

${ }^{10}$ C. F. Frazatto e K. R. S. Bigatto realizaram a pesquisa e o levantamento dos dados; elaboração e revisão do texto. 


\section{Abstract}

\section{The mental health community organizations from Quebec (Canada)}

This study presents the Mental Health Community Organizations (MHCO) from Quebec (Canada). The authors draw up reflections considering its origin, insertion into the public health system, principles, characteristics and formats. The MHCO are autonomous, community-based services that provide nonprofit activities in health and social service fields. A descriptive, qualitative study based on a nonsystematic review of the literature was done. The results point to the emergence of the MHCO in a context of dehospitalization of patients, but without enough resources replacing the psychiatric hospital. They were consolidated as an alternative to traditional psychiatry, recognized by the government as part of mental health care, and partially financed by the State. The MHCO share some principles, but they materialize in several formats. They stand out for encouraging the defense of rights, and socially reintegrating people in psychological distress. However, there are limitations considering their reach and interaction with public establishments, and the role of the State over these institutions is questioned. We conclude by pointing out similarities and differences between mental health assistance promoted by the MHCO from Quebec and by Brazil. It is necessary to continue dialoguing, aiming to establish policies and practices in mental health that guarantee communitybased care.

> Keywords: mental health; mental health community organizations; Quebec. 